\title{
Curcumin Inhibited Podocyte Cell Apoptosis and Accelerated Cell Autophagy in Diabetic Nephropathy via Regulating Beclin I/UVRAG/Bcl2
}

This article was published in the following Dove Press journal: Diabetes, Metabolic Syndrome and Obesity: Targets and Therapy

\author{
Pingping Zhang \\ Jie Fang \\ Jianping Zhang \\ Shuxia Ding \\ Dongmei Gan
}

Department of Endocrinology, Ningbo Women and Children's Hospital, Ningbo City, Zhejiang Province, People's Republic of China
Correspondence: Dongmei Gan Ningbo Women and Children's Hospital, 339 Liuting Street, Haishu District, Ningbo City, Zhejiang Province 315000, People's Republic of China Email DongmeiGanI@I63.com
Introduction: Curcumin has various biological properties including being antiinflammatory and antidiabetic. Podocyte apoptosis and autophagy dysfunction have been found to be responsible for the development of diabetic nephropathy (DN). Thus, the aim of the study was to investigate the effects of curcumin on the podocyte apoptosis and autophagy in DN and clarify its potential mechanisms.

Methods: The mice with DN induced by injection of streptozotocin were treated with curcumin by gavage at a dose of $200 \mathrm{mg} / \mathrm{kg} /$ day for 8 weeks. The serum lipid levels were detected by total cholesterol (TC) and triglyceride (TG) kits at different time points. Renal damage was assessed by detecting urine albumin, serum creatinine (Scr), HE staining and PAS staining. The renal impairment was detected by immunohistochemical staining and TUNEL staining. Western blot assay tested the expression of autophagy-related and apoptotic-related proteins in vivo and vitro. The viabilities and apoptosis of MPC5 cells exposed to high glucose (HG) or curcumin were respectively detected by CCK-8 assay and flow cytometry.

Results: The results showed that curcumin significantly decreased the progress of DN possibly via increasing autophagy and inhibiting apoptosis of renal cell in DN mice. Besides, podocyte marker proteins (podocalyxin and nephrin) were markedly increased in DN mice by curcumin treatment. The autophagy-related proteins LC3, p62, Beclin1, UVRAG and ATG5 were significantly affected in DN mice by curcumin, along with reducing expression of pro-apoptotic protein Bax and caspase-3 and increasing antiapoptotic protein Bcl-2. In vitro, curcumin increased the viabilities and inhibited apoptosis of MPC5 cells exposed to high glucose (HG). In addition, the podocyte autophagy was enhanced partly via regulating beclin1/UVRAG.

Discussion: Together, the results showed that curcumin inhibited podocyte apoptosis and accelerated cell autophagy via regulating Beclin1/UVRAG/Bcl2. Thus, the study showed that curcumin exerted significantly protective effects in DN.

Keywords: curcumin, diabetic nephropathy, podocyte apoptosis, autophagy, Beclin1/ UVRAG/Bcl2

\section{Introduction}

$\mathrm{DN}$ is a common microvascular complication of diabetic patients, ${ }^{1}$ the main clinical symptoms of which are renal enlargement and glomerular volume increase, causing the decreasing renal functions including proteinuria, glomerular sclerosis and renal tubule fibrosis. $^{2,3}$ The abnormal expression of the extracellular matrix is the typical clinical symptom of DN, ${ }^{4}$ which aggregates DN and eventually leads to glomerular mesangial expansion, tubular fibrosis and irreversible deterioration of renal function. DN is 
a major cause of chronic kidney disease worldwide and one of the most important long-term complications for diabetes patients in morbidity and mortality. ${ }^{5}$ There are currently no effective treatments for DN other than symptomatic relief such as glucose control, dialysis and kidney transplantation. ${ }^{6}$ However, the high morbidity and mortality rates of DN have not reduced. ${ }^{7}$ Therefore, the effective and novel therapeutic strategies are critical for patients with DN.

Podocytes are one of the important components of capillary filtration in renal tubules, ${ }^{8}$ the loss and impairment of which are related to the initiation and progression of DN. The proliferation and regeneration of podocytes in DN are limited. ${ }^{9,10}$ Furthermore, the highly specialized and terminally differentiated podocytes are unable to proliferate, so autophagy plays an important role in maintaining the normal structure and function of podocytes. ${ }^{11}$ Autophagic dysfunction is involved in the loss of the podocytes, resulting in a large amount of proteinuria in DN patients. ${ }^{12}$

Autophagy is the major intracellular degradation system by which cytoplasmic materials are delivered to the lysosome and then degraded. ${ }^{13}$ Autophagy can maintain intracellular homeostasis and cell integrity. Thus, it is important for cell survival, differentiation and metabolism. ${ }^{14,15}$ Recent studies have demonstrated the important role of apoptosis and autophagy in the development and progression of DN. ${ }^{16,17}$ Moreover, the inhibition of autophagy in podocytes leads to renal dysfunction in diabetes. ${ }^{18}$

Curcumin possesses a variety of biological properties beneficial to living beings, including anti-inflammatory and antidiabetic. ${ }^{19-21}$ The studies have found that curcumin inhibits cell proliferation and induces apoptosis in several tumors. $^{22-25}$ Besides, curcumin has been reported to enhance autophagy-related cell death, ${ }^{26}$ and induce cell apoptosis through lysosomal membrane permeabilization-medicated autophagy or downregulating lncRNA. ${ }^{27,28}$ What's more, curcumin exerts protective effects through promoting autophagy and ameliorating apoptosis in diabetic cardiomyopathy. ${ }^{29}$ Thus, the study mainly focused on the effects of curcumin on DN in vivo and vitro, and then analyzed its potential mechanism in apoptosis and autophagy of podocytes.

\section{Materials and Methods}

\section{Experimental Mouse Model}

The specific pathogen-free (SPF) male balb/c mice weighing 18-22 $\mathrm{g}$ at 8 weeks were purchased by Shanghai experimental animal center, Chinese Academy of Sciences (number of animal license: SCXK2013-0006). The mice were housed at $22^{\circ} \mathrm{C}$ with $12 \mathrm{~h}$ light-dark cycle and free access to standard rodent feed, which were randomized into DN and control group. $12 \mathrm{~h}$ after fasting, the DN group was induced by intraperitoneally injecting streptozotocin for consecutive 3 days (STZ; Sigma, USA) at a dose of $55 \mathrm{mg} / \mathrm{kg}$ (STZ dissolved in $0.1 \mathrm{~mol} / \mathrm{L}$ sodium citrate). Meanwhile, the control group was administered with buffered saline of the same volume. The studies showed that $55 \mathrm{mg} / \mathrm{kg}$ of STZ could induce DN in mouse or rats. ${ }^{30,31}$ Moreover, preliminary experiments have also proved this. After $72 \mathrm{~h}$, the blood from the tail top was collected to detect blood glucose through a glucometer. The blood glucose level (fasting blood glucose $\geq 16.7 \mathrm{mmol} / \mathrm{L}$ for 3 consequent days) indicated that the diabetic mouse model was established successfully. ${ }^{32,33}$ The experimental mice were randomly allocated to the following groups ( $\mathrm{n}=6$ per group): Group 1: normal control (NC) group, Group 2: DN group, Group 3: curcumin group. The curcumin group was given $200 \mathrm{mg} / \mathrm{kg}$ curcumin ( $\geq 98 \%$ by HPLC Yantai New Era Health Industry Co., Ltd, Shangdong, China, dissolved in carboxymethyl cellulose $\mathrm{Na}$ solution (CMC-Na)) once a day for 8 weeks by intragastric administration. The $\mathrm{NC}$ and DN groups were given 1\% CMC-Na at a dose of $200 \mathrm{mg} / \mathrm{kg}$ once a day for 8 weeks by intragastric administration. The dose of curcumin has been proven to have significantly protective effects in diabetic animal models. ${ }^{29,34}$ Blood glucose was detected at 9, 18, 27, 36, 43, 56 days using a glucometer via tail vein after establishing a diabetic mouse. At day36, 56, the serum was collected which isolated from blood sample by eyeball extirpating. The serum was stored in $-20^{\circ} \mathrm{C}$ refrigerator. The mice were sacrificed with ether.

The study was performed following the Ethical Guidelines of the International Association for the Study of Diabetes. All experimental protocols were approved by Institutional Animal Care and Use Committee of Ningbo University and conducted in accordance with the National Institutes of Health (NIH) Guide for the Care and Use of Laboratory Animals. All mice from each group were housed in metabolic cages to collect $24 \mathrm{~h}$ urine samples. The right kidneys were removed and immediately frozen in liquid nitrogen and stored at $-80^{\circ} \mathrm{C}$ at 8 weeks after curcumin treatment. The left kidneys were fixed with $10 \%$ formaldehyde and embedded with paraffin.

\section{The Detection of Total Cholesterol (TC) and Triglyceride (TG) of Serum}

The blood in the mice was collected by eyeball extirpating, which then was centrifuged at $3000 \mathrm{r} / \mathrm{min}$ for $10 \mathrm{~min}$ to get 
serum. The $\mathrm{TC}$ or $\mathrm{TG}$ levels in serum were separately detected by TC or TG kits according to manufacturer's instructions (Changchun Huili BioTechco., LTD. China)

\section{Assessment of Renal Function}

The mouse was placed into a mouse metabolic cage 1 day before mice were sacrificed. The urine samples were collected for a period of $24 \mathrm{~h}$. BCG (Bromocresol Green) albumin assay kit (sigma aldrich, America) was used to detect the levels of urine albumin. Urinary albumin excretion rates (UAER) were calculated using the formula: $\mathrm{UAER}=$ urine albumin*urine volume of $24 \mathrm{~h}$. The blood was collected through removing eye before mice were sacrificed and centrifuged to get serum. Serum creatinine levels (Scr) were analyzed using a serum creatinine kit (R\&D, America).

\section{Hematoxyline-Eosin (HE) Staining}

The kidney tissues were fixed with $10 \%$ buffered formalin at room temperature for $48 \mathrm{~h}$, dehydrated, and embedded in paraffin. The sections were stained with hematoxylin and eosin H\&E. Blinded analysis of renal tissues were performed using a light microscope. A board-certified pathologist examined pathological alterations of renal tissues.

\section{PAS Staining}

Paraffin section of renal tissues was dewaxing hydration and then was rinsed with distilled water. The section was soaked into $1 \%$ periodate acid solution and oxidized for $10 \mathrm{~min}$, and then was immersed into Schiff Reagent for $40 \mathrm{~min}$ without light (Jiancheng, Nanjing, China). Rinsing with running water until the tissue turned pink. The renal tissues were used to stain nuclei with Hematoxylin dye for 3-5 min and differentiated with $0.5-1.0 \%$ alcohol hydrochloride for $5 \mathrm{~s}$ which then was washed with double-distilled water. After that, the section was dehydrated with anhydrous ethanol and sealed with neutral gum after transparent by xylene. The glycogen mucus protein presented fuchsia and the nucleus showed blue under the microscope.

\section{Immunofluorescence Staining}

Renal tissues were embedded carefully without any damage on dry ice. Sections of $5 \mu \mathrm{m}$ were cut and performed with Immunofluorescence staining. Alternatively, podocytes were permeabilized with Triton X-100 and washed 3-times with PBS. Briefly, sections of $5 \mu \mathrm{m}$ were cut and fixed in $10 \%$ neutral buffered formalin; the slices were then washed with PBS and treated with $0.2 \%$ Triton $\mathrm{X}-100$; podocalyxin, nephrin and LC3 antibodies were incubated with the slices after blocking with 1\% BSA at $4^{\circ} \mathrm{C}$ overnight, washed with PBS, and then incubated with Cy3-or fluorescein isothiocyanate (FITC)-conjugated goat anti-rabbit $\mathrm{IgG}$ antibodies in the dark for $1 \mathrm{~h}$ at $37^{\circ} \mathrm{C}$. The nuclei were then stained with 4',6-diamidino-2-phenylindole (DAPI, Genview) for $5 \mathrm{~min}$ in the dark. Finally, the coverslips were mounted on slides with an anti-fluorescence quencher, and the stained podocytes were observed with a Leica DM60008 microscope.

\section{TUNEL Staining}

Renal tissues were embedded on dry ice. Sections of $5 \mu \mathrm{m}$ were cut and fixed with $4 \%$ paraformaldehyde for $10 \mathrm{~min}$, then washed using PBS for 5 min for 3 times. Podocyte apoptosis was analyzed by using TUNEL staining in accordance with the manufacturer's instruction (Promega, Madison, USA). The sections were soaked into a blocking solution for $10 \mathrm{~min}$ and then immersed into $0.1 \%$ TritonX-100 for $1 \mathrm{~min}$. The sections were incubated with tunnel solution for $60 \mathrm{~min}$ at room temperature, then washed with PBS for $5 \mathrm{~min}$ for 3 times. After that, DAPI was added to stain nuclei after dilution in PBS at a ratio of 1:1000. Anti-quench sealant was dropped on the section surface. Fluorescence microscope was used to take photographs.

\section{Western Blot Assay}

The renal tissues $(20 \mathrm{mg})$ and podocyte cells were collected and lysed with RIPA lysis buffer $(250 \mu \mathrm{L})$ (Beyotime, Haiman, China). After centrifugation at $12000 \mathrm{r} / \mathrm{min}$ for $20 \mathrm{~min}$, protein concentration was quantified using a Bio-Rad protein assay kit (Bio-Rad). Protein samples (50 $\mu$ g loading protein/hole) were separated by $12 \%$ SDS-PAGE, then electrophoretically transferred onto polyvinylidene difluoride (PVDF) membranes (Bio-Rad). The membranes were incubated in primary antibodies (LC3: 1:1500, beclin1: 1:600, p62: 1:1000, UVRAG: 1:1000, ATG5: 1:2000, GAPDH: 1:1000. Abcam, England) (Bax: 1:200, caspase-3: 1:500, Bcl-2: 1:200. Santa Cruz, America) at $4^{\circ} \mathrm{C}$ overnight. Then, membranes were incubated with horseradish peroxidase-coupled secondary antibody (1:5000) for $1 \mathrm{~h}$ at room temperature (Santa Cruz Biotechnology). The signals were detected by chemiluminescence detection kit (Thermo Fisher Scientific). The protein bands were visualized by autoradiography and quantified by ImageJ software (National Institutes of Health, Bethesda, MD, USA). Finally, the gray value ratio of the target strip to the 
internal reference strip was considered as an indicator of the relative protein expression levels.

\section{Podocyte Culture}

The mouse podocyte cell (MPC5) line was purchased from the agency company of ATCC: Shanghai lianmai biological engineering co. LTD. MPC5 was cultured in RPMI 1640 medium (GENOM, Hangzhou, China) at $37^{\circ} \mathrm{C}$ under an atmosphere of $5 \% \mathrm{CO} 2$, supplemented with $10 \%$ fetal bovine serum and recombinant interferon gamma (IFN- $\gamma$ ) that induced differentiation and maturation of MPC5 cells. The differentiated podocytes at $75 \%$ confluency were digested with trypsin and then performed to passage. The cells were continued to culture for $10-14$ days without IFN- $\gamma$ to fully get full differentiation and maturation. The podocytes were divided into the following groups: control (D-glucose, Sigma, America, $5.5 \mathrm{mmol} / \mathrm{L}$ ), high glucose $(30 \mathrm{mmol} / \mathrm{l}),{ }^{35,36}$ or high glucose plus curcumin at three different concentration $(20 \mu \mathrm{m}, 40 \mu \mathrm{m}, 80 \mu \mathrm{m})$ and control group.

\section{Cell Proliferation Assay}

The Cell Counting Kit-8 (CCK-8, Dojindo Laboratories, Japan) was used to measure cell proliferation according to the manufacturer's instructions. Podocytes were seeded into 96-well plates at a density of $5 \times 10^{3}$ cells per well with 100 $\mu \mathrm{L}$ of cell culture medium and incubated with $5 \% \mathrm{CO} 2$ at 37 ${ }^{\circ} \mathrm{C}$. At the indicated time points, $10 \mu \mathrm{L}$ CCK- 8 was added to each well. After incubation for $2 \mathrm{~h}$, the absorbance at 450 $\mathrm{nm}$ was detected by ELx800 Absorbance Reader (BioTek Instruments, Inc., Winooski, VT, USA).

\section{Flow Cytometry Analysis}

MPC5 cells were collected after centrifugation. The total number of cells in each group must be more than $5^{*} 10^{5}$ cells. The Annexin V-FITC/PI Apoptosis Kit (Keygen Biotech, Nanjing, China) was used to analyze cell apoptosis according to the manufacturer's protocol. Podocytes were briefly digested with $0.25 \%$ trypsin and then washed with icecold PBS twice. $500 \mu \mathrm{L} \mathrm{1*}$ Binding Buffer was used to resuspend cells. Then, AnnexinV reagent $(5 \mu \mathrm{L})$ labeled with FITC was added, followed by PI of $10 \mu \mathrm{L}$. After incubation under avoiding light at room temperature for $15 \mathrm{~min}$. Apoptosis levels were analyzed using a flow cytometer (LSRFortessa $^{\mathrm{TM}}$ SORP, Becton, Dickinson and Company, Franklin Lakes, NJ, USA) and FACS scan software (Becton, Dickinson and Company).

\section{Statistical Analysis}

GraphPad Prism software was used to perform statistical analyses. All values are presented as the mean $\pm \mathrm{SD}$. The $t$-test was used to assess the differences between the two groups. Three or more group comparisons were analyzed using one-way ANOVA. $\mathrm{P}<0.05$ was considered to be statistically significant.

\section{Results}

\section{Curcumin Decreases TC and TG Levels in DN Mouse}

Comparing to the control group, the serum TC and TG levels in the DN group presented a significant increase and showed an increasing trend with the increase of weekly age. 36 days or 56 days after treatment, curcumin significantly reduced serum TC and TG levels in DN mouse as shown in Table 1. Compared with 36 days and 56 days after administration, the serum TG and TC contents of mice in each treatment group showed a decreasing trend, but the difference was not significant.

\section{Curcumin Improves the Renal Function of DN Mouse}

The experiment mice were treated with or without curcumin for 8 weeks, and the albuminuria and urine creatinine were detected in the model group compared with the normal group. After curcumin treatment, the levels of UAER, Scr and blood glucose were obviously lower than without in the curcumin group (Figure 1A-C, Table 1). Together, these results suggested that curcumin improved

Table I The Effects of Curcumin on Blood Glucose, Serum Total Cholesterol (TC, TG) of Diabetic Mice by STZ

\begin{tabular}{|l|l|l|l|l|}
\hline Day & Group & BG $(\mathbf{m m o l} / \mathbf{l})$ & TC $(\mathbf{m m o l} / \mathbf{l})$ & TG $(\mathbf{m m o l} / \mathbf{l})$ \\
\hline 0 & NC & $6.51 \pm 1.34$ & $2.90 \pm 0.21$ & $1.05 \pm 0.21$ \\
& DN & $18.96 \pm 2.4 I^{* * *}$ & $4.96 \pm 0.92^{* *}$ & $2.21 \pm 0.36^{* *}$ \\
& Curcumin & $18.65 \pm 3.04^{* * *}$ & $5.01 \pm 1.03^{* *}$ & $1.97 \pm 0.32^{* * \#}$ \\
\hline \multirow{2}{*}{36} & NC & $5.90 \pm 1.28$ & $3.10 \pm 0.60$ & $1.13 \pm 0.196$ \\
& DN & $18.00 \pm 2.01^{* * *}$ & $5.23 \pm 0.84^{* *}$ & $2.54 \pm 0.32^{* *}$ \\
& Curcumin & $13.17 \pm 2.31^{* * * \#}$ & $4.40 \pm 0.83^{* * \#}$ & $1.92 \pm 0.4 I^{* * \#}$ \\
\hline \multirow{2}{*}{56} & NC & $7.21 \pm 1.41$ & $3.40 \pm 0.62$ & $1.22 \pm 0.19$ \\
& DN & $20.61 \pm 1.51^{* * *}$ & $5.63 \pm 0.84^{* *}$ & $2.59 \pm 0.29^{* *}$ \\
& Curcumin & $10.09 \pm 1.78^{* * \# \#}$ & $4.1 \pm 0.94^{* \#}$ & $1.73 \pm 0.57^{* \#}$ \\
\hline
\end{tabular}

Notes: ${ }^{*} P<0.05,{ }^{* * P}<0.01,{ }^{*} * * P<0.001$ vs control group; ${ }^{\# P}<0.05,{ }^{\#} P<0.01$, \# $\mathrm{P}<0.001$ vs diabetic group.

Abbreviations: NC, normal group; DN, diabetic group; curcumin, diabetic+cucu$\min$ group, $\mathrm{n}=6$. 

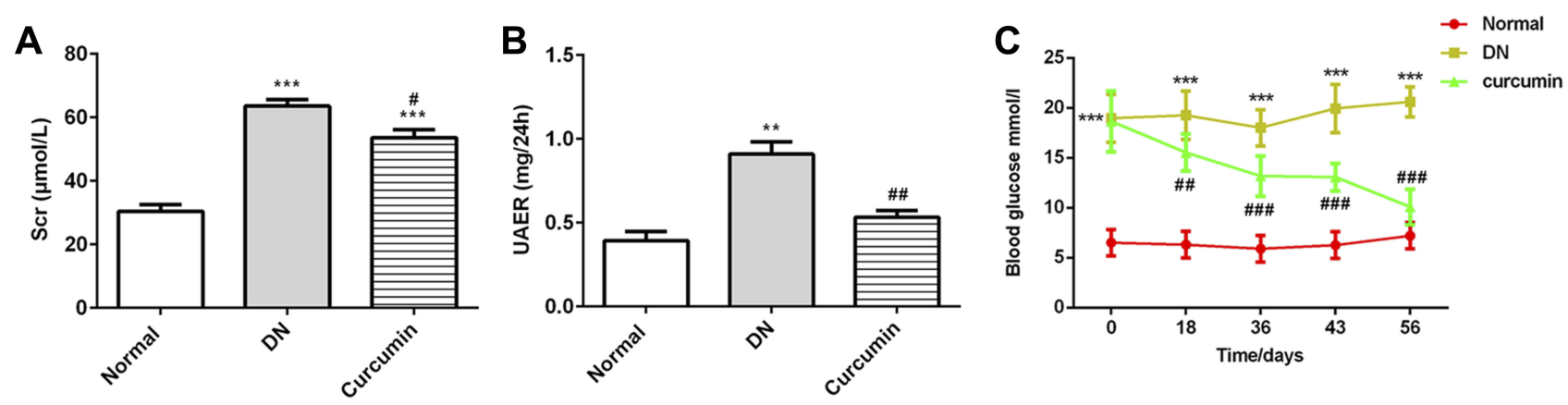

Figure I Curcumin decreased the levels of Scr, UAER and blood glucose in DN mice. (A) The levels of Scr were detected by the urine Creatinine Detection Kit. (B) The levels of urine albumin were measured by BCG albumin assay kit. (C) The glucose levels were detected at $0,18,36,43$ and 56 days after curcumin or CMC-Na treatment. Data were shown as mean \pm SD, $n=6$. ${ }^{* *} p<0.01$ VS Normal. ${ }^{* * *} p<0.001 .{ }^{\#} p<0.01$ VS DN. ${ }^{\# \#<0.01 . ~}{ }^{\# \#} p<0.001$.

the renal function and reduced the levels of albuminuria, serum creatinine and blood glucose in DN mouse.

\section{Curcumin Alleviates the Pathological Changes of the Kidneys in DN Mouse}

Kidney tissues were collected for HE and PAS staining. The HE staining showed the pathological changes of the kidneys in DN mice as showed in Figure 2A. The results showed that the glomerular capillary lumen was uniform and without stricture, and the structure of renal tubules was clear, closely arranged back to back. The basement membrane of epithelial cells was intact, well arranged and no inflammatory cell infiltration in the control group. Meaningfully, glomerular hypertrophy and deformity, mesangial cell proliferation, renal tubular epithelial degeneration, some tubular lumen dilatation and inflammatory cell infiltration were observed in the DN group. Interestingly, the degeneration of renal tubular was significantly reduced, and the infiltration of inflammatory cells was significantly reduced in the curcumin group. Cell nucleus was blue and the glomerular basement membrane was purplish-red in PAS staining. The results indicated that curcumin significantly reduced the content of PAS-positive materials in DN (Figure 2B). Therefore, glomerular mesangial hyperplasia in DN was markedly decreased by curcumin. Overall, these data indicated that curcumin alleviates the pathological changes of the kidneys in DN mice.

\section{Curcumin Inhibited the Renal Cell Apoptosis in DN Mouse}

Next, immunohistochemical staining showed the expression of podocalyxin and nephrin which were podocyte marker proteins. As shown in Figure 3A, the expressions of podocalyxin and nephrin were lower in the DN group than the control group. It suggested that the renal podocyte damage appeared in DN mice. The podocalyxin and nephrin expression were higher in the curcumin group than the DN group, which indicated that curcumin has protective effects on podocytes. To observe the effects of curcumin on renal cell apoptosis, tunnel staining suggested that curcumin significantly reduced renal cell apoptosis in DN mice (Figure 3B). Western blot assay showed increased anti-apoptotic protein Bcl-2 and decreased pro-apoptotic protein Bax and caspase-3 by curcumin treatment (Figure 3C). These data implied that curcumin alleviated the renal cell apoptosis in DN mice.

\section{Curcumin Promoted the Renal Cell Autophagy in DN Mouse}

We next evaluate the effect of autophagy in vitro. First of all, immunofluorescence staining of LC3 showed that autophagosome was notably increased (Figure 4A). Moreover, the ratio of LC3II/LC3I in DN mice was significantly increased by curcumin (Figure 4B) which implied that curcumin increased autophagy. Besides, p62 levels were lower in the curcumin group than the DN group. Thus, the degradation pathway of autophagy lysosomes was not blocked. The results indicated that curcumin enhanced autophagy. Besides, the expression levels of proteins (beclin1, UVRAG and ATG5) involved in autophagy were determined by Western blot. Curcumin significantly increased the levels of beclin1, UVRAG and ATG5 (Figure 4B). Thus, curcumin increased the autophagy of the renal cell in DN mouse.

\section{Curcumin Increased Cell Activity and Inhibited Apoptosis in Podocyte Induced by HG}

To study the effect of curcumin on HG-induced apoptosis, in podocytes. MPC5 cells were incubated in medium containing 


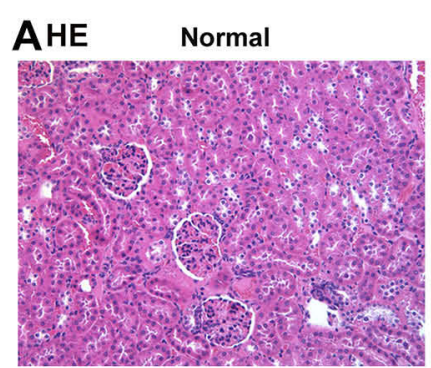

B PAS Normal

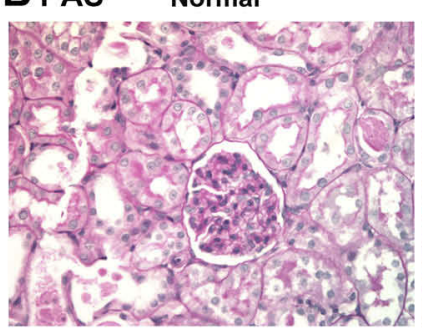

DN

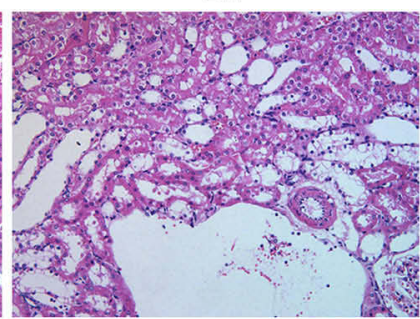

DN

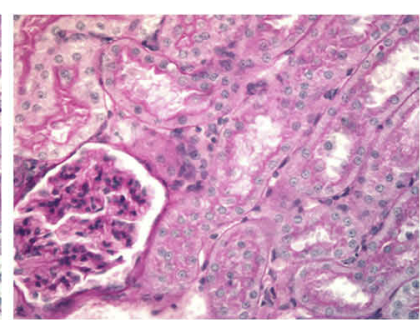

Curcumin

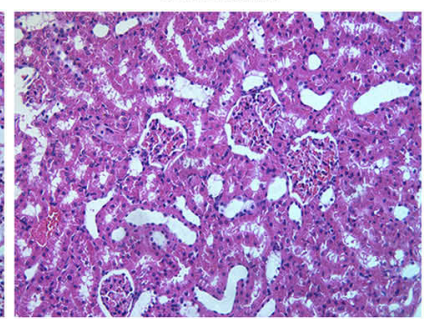

Curcumin

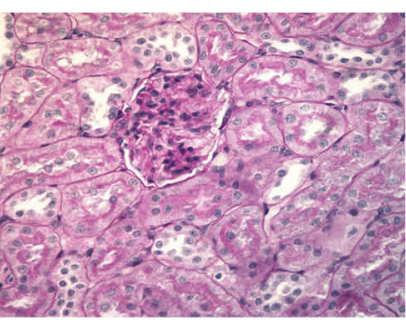

Figure 2 The pathological changes of the kidneys after curcumin treatment. (A) HE staining showed the pathological changes in renal. (B) PAS staining the pathological changes in renal.

A

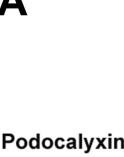

B

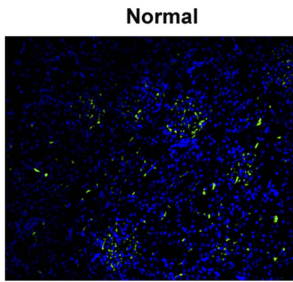

Nephrin

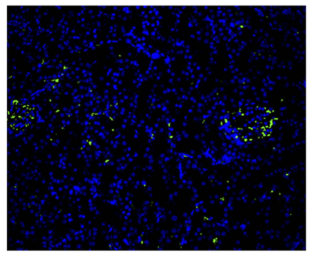

Normal

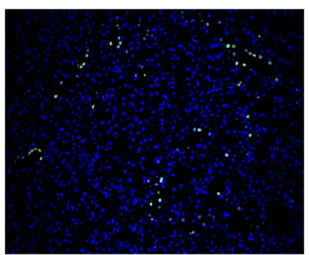

Bax

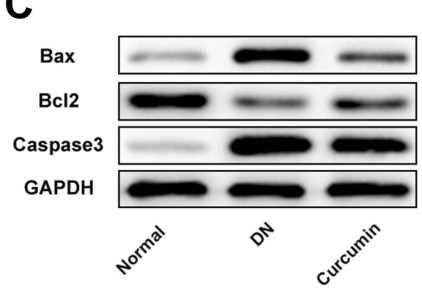

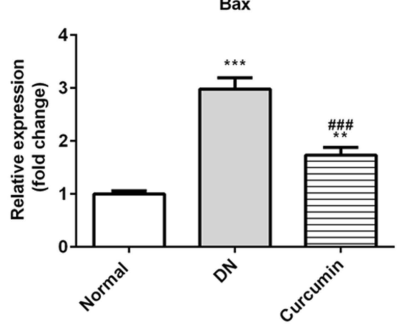

DN

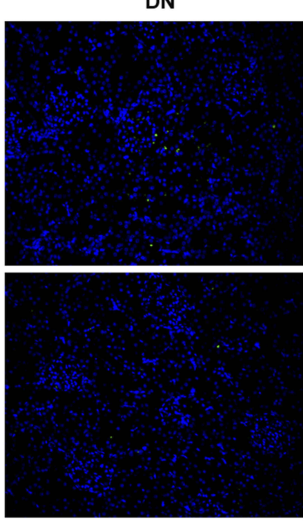

DN
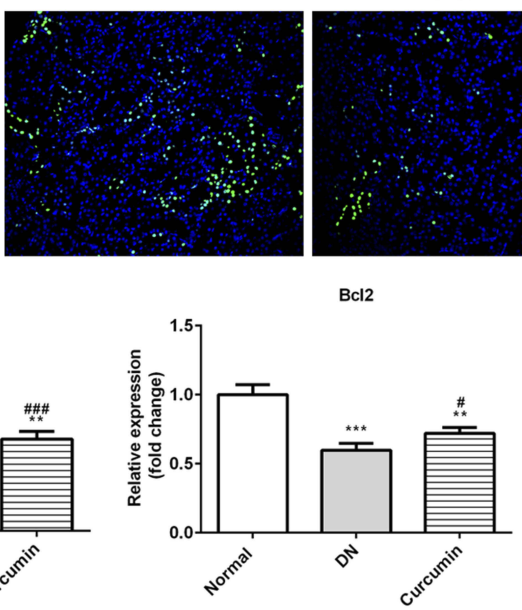

Curcumin

Curcumin
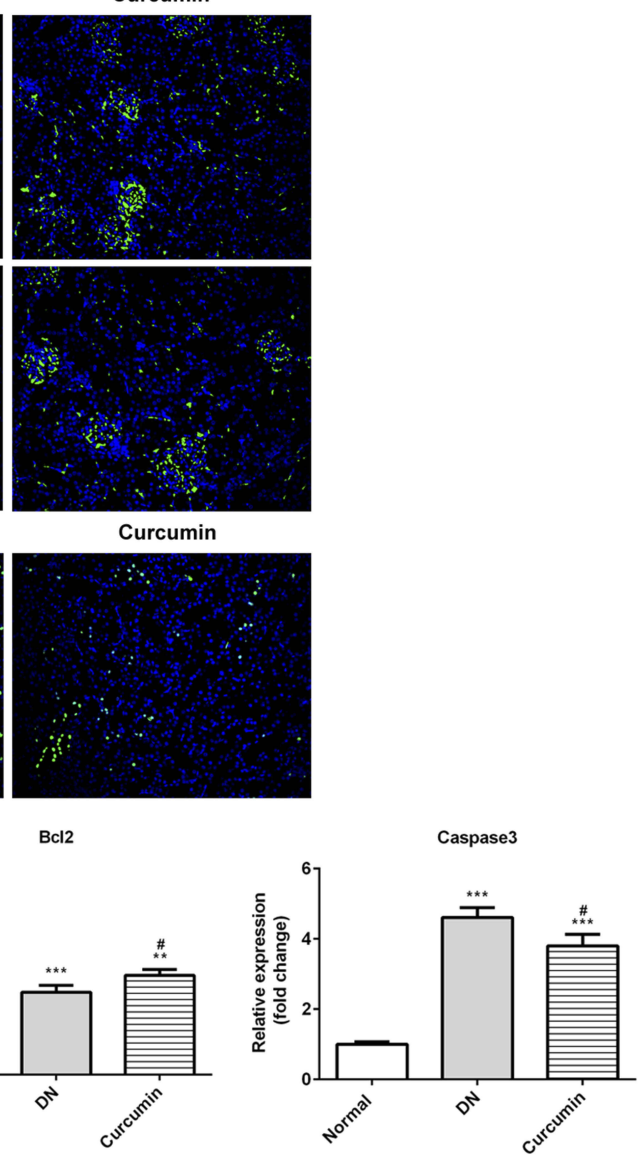

Figure 3 Effect of curcumin on renal cell apoptosis in DN mice. (A) The protein levels of nephrin and podocalyxin in the DN mouse renal were detected by Immunofluorescence staining. (B) The cell apoptosis was detected by tunnel staining. (C) Western blot assay showed that the expression of anti-apoptotic protein $\mathrm{Bcl}-2$ and pro-apoptotic protein Bax and caspase-3 in DN mouse. Data were shown as mean \pm SD, $n=6 . * * p<0.01$ VS Normal. ${ }^{*}<<0.05$ VS DN.***p<0.00I.

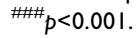




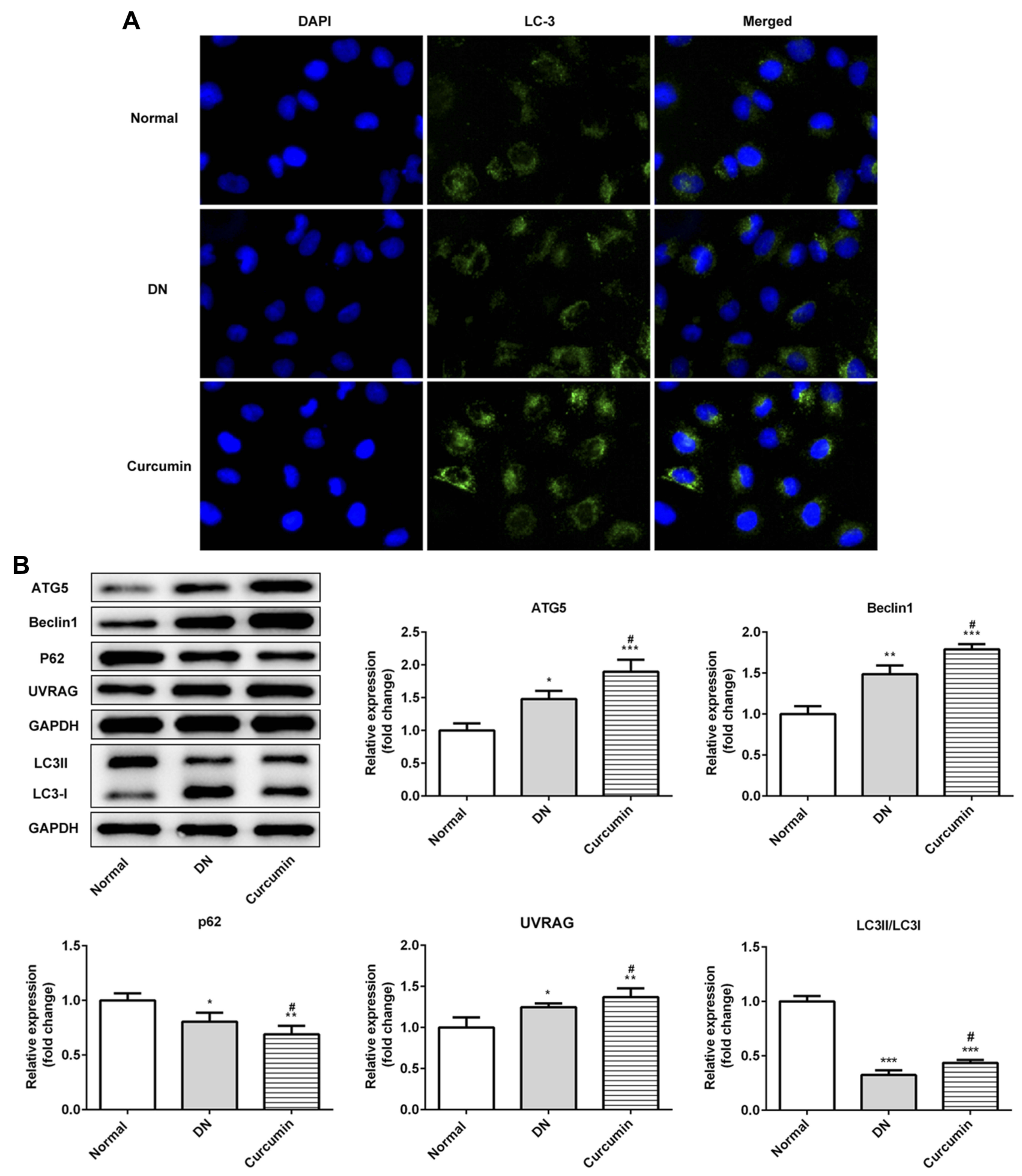

Figure 4 Effect of curcumin on podocyte autophagy in DN mice. (A) The protein levels of LC3 in the DN mouse renal were detected by Immunofluorescence staining. (B) Western blot assay showed that the expression of beclin I, P62, LC3, UVRAG and ATG5 in DN mouse. Data were shown as mean \pm SD, $n=6$. * $p<0.05$ VS Normal. ${ }^{\#} p<0.05$ VS DN. ${ }^{* *} p<0.01$. $* * * p<0.001$.

normal glucose $(5.5 \mathrm{mmol} / \mathrm{l})$, high glucose $(30 \mathrm{mmol} / \mathrm{L})$, or high glucose plus curcumin at three different concentration $(20 \mu \mathrm{m}, 40 \mu \mathrm{m}, 80 \mu \mathrm{m})$ and control group for $48 \mathrm{~h}$ and $74 \mathrm{~h}$. At $48 \mathrm{~h}, \mathrm{CCK}-8$ assay results showed that curcumin promoted the cell activities in a dose-dependent manner compared with the high glucose group. The cell activities in curcumin administration were higher at $72 \mathrm{~h}$ than $48 \mathrm{~h}$ (Figure $5 \mathrm{~A}-\mathrm{C}$ ). Next, Annexin V-FITC/propidium iodide (PI) staining was 
$\mathbf{F}$

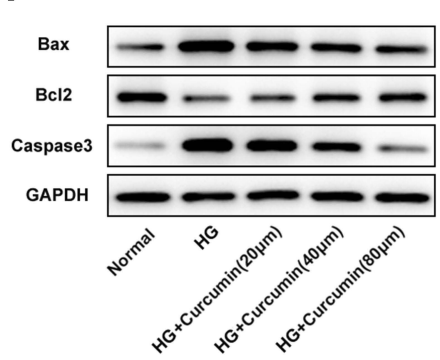

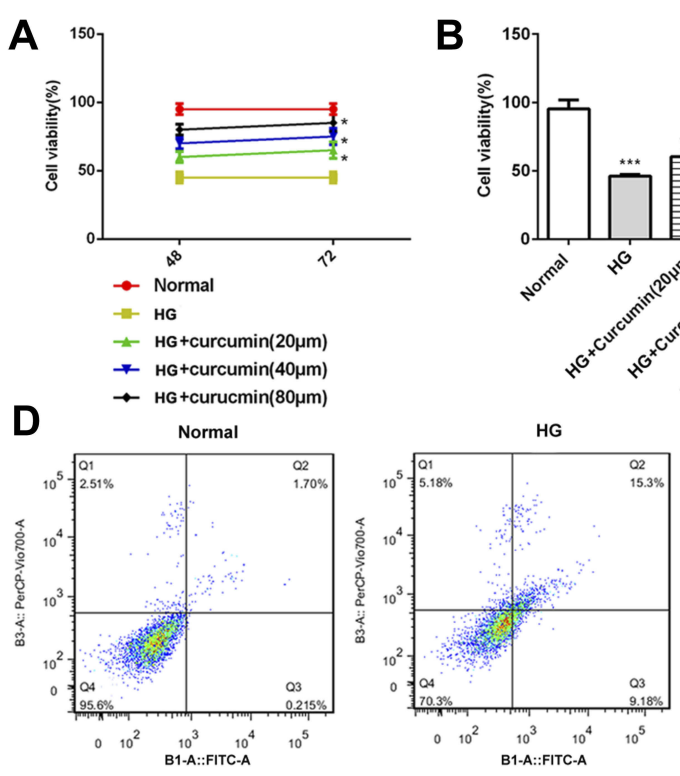
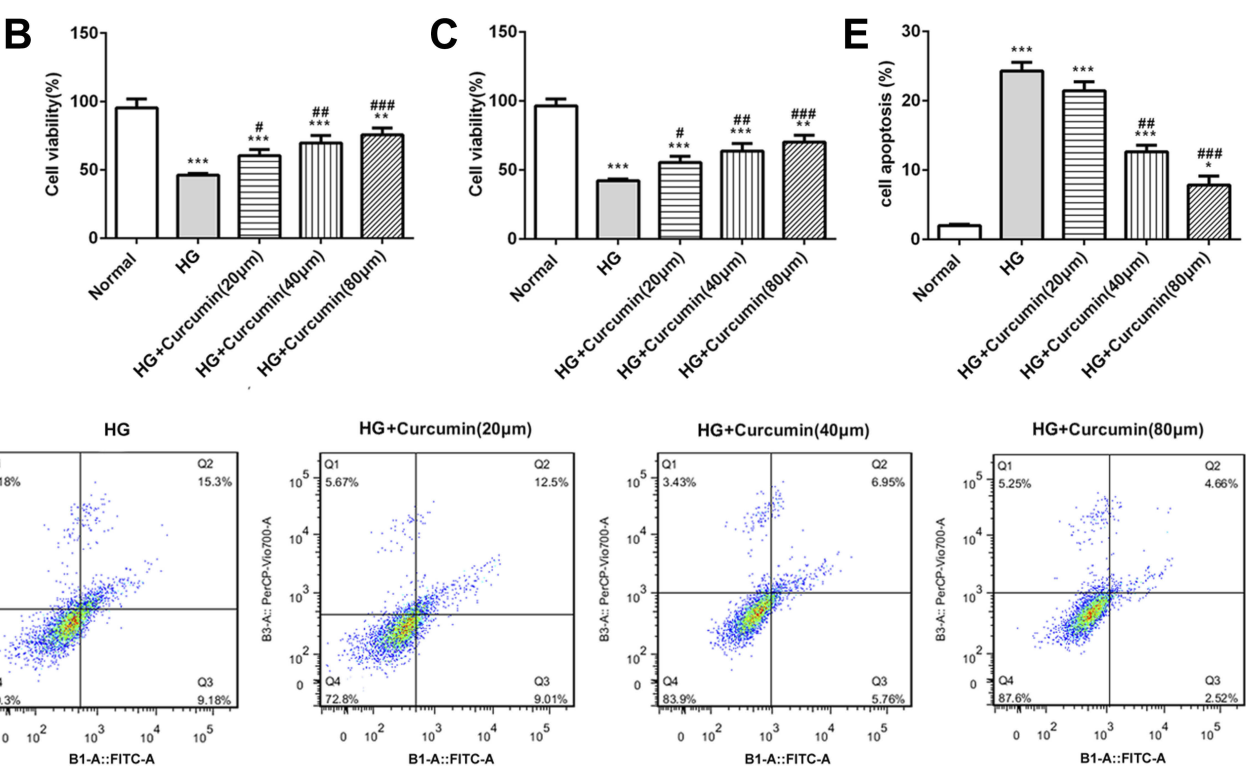

Bax
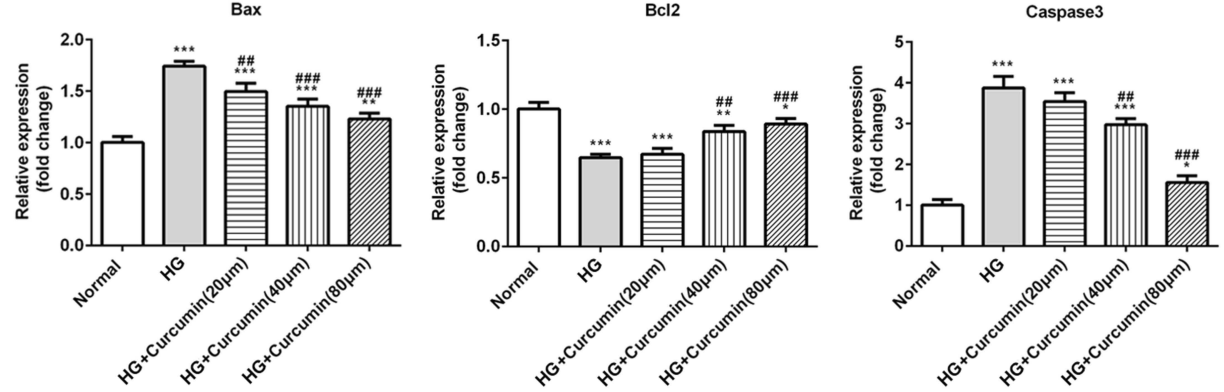

Figure 5 Effect of curcumin on podocyte activity and apoptosis induced by high glucose. (A-C) Podocytes were cultured with normal glucose (5.5 mM), high glucose ( 30 $\mathrm{mmol} / \mathrm{l})$ and curcumin at different concentrations $(20,40,80 \mu \mathrm{M})$ for 48 or $72 \mathrm{~h}$. The relative cell viability was assessed with CCK-8 and expressed as percent podocyte survival relative to that of the normal cells. (D and $\mathbf{E})$ AV-FITC/PI staining was performed to quantify the apoptosis rates via flow cytometry. (F) Western blot assay showed that the expression of anti-apoptotic protein Bcl-2 and pro-apoptotic protein Bax and caspase-3 in podocytes. Data were shown as mean \pm SD. $* p<0.05$ VS Normal. ${ }^{*}<0.05$ VS HG: high glucose. (HG+cucumin): high glucose+curcumin. $* * p<0.01 . * * p<0.001 .{ }^{*} p<0.01 .{ }^{*} p<0.001$.

performed to quantify the podocyte apoptosis via flow cytometry assay. As shown in Figure 5D and E, the rate of apoptotic cells treated with high glucose was significantly increased than control, and the effects of the high glucose treatment were inhibited by curcumin. Further, Western blot assay indicated the expression of antiapoptotic protein $\mathrm{Bcl}-2$ and proapoptotic protein Bax and caspase-3. Curcumin significantly increased the expression of Bcl-2 and decreased the expression of Bax and caspase- 3 in a dose-dependent manner (Figure 5F). Therefore, curcumin increased the activities and inhibited apoptosis of podocyte induced by high glucose.

\section{Curcumin Increased Cell Autophagy via Regulating Beclin I/UVRAG in Podocyte Induced by HG}

Immunofluorescence staining determined the expression of LC2II/LC3I and in control, high glucose, or high glucose plus curcumin at three different concentrations $(20 \mu \mathrm{m}$,
$40 \mu \mathrm{m}, 80 \mu \mathrm{m})$. Our results suggested that curcumin significantly increased the ratio of LC2II/LC3I compared with normal and high glucose group (Figure 6A and B). Further, the expression proteins (beclin1, p62, UVRAG and ATG5) involved in autophagy were determined in control, high glucose, or high glucose plus curcumin at three different concentrations $(20 \mu \mathrm{m}, 40 \mu \mathrm{m}, 80 \mu \mathrm{m})$ by Western blot analysis. Curcumin significantly increased the expression levels of beclin1, UVRAG and ATG5 and decreased the expression of p62 in dose-dependent manner compared with high glucose group (Figure 6B). These data suggested that curcumin increased podocyte autophagy possibly through regulating Beclin1/UVRAG under high glucose treatment.

\section{Discussion}

Our study showed that curcumin significantly improves renal impairment in DN mice, followed by improved 
A
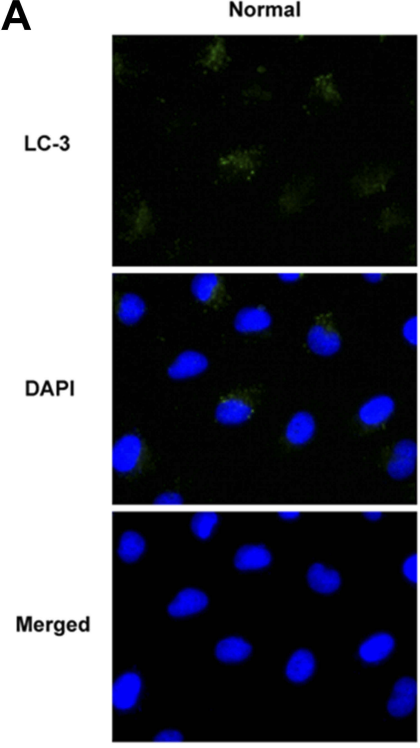

B
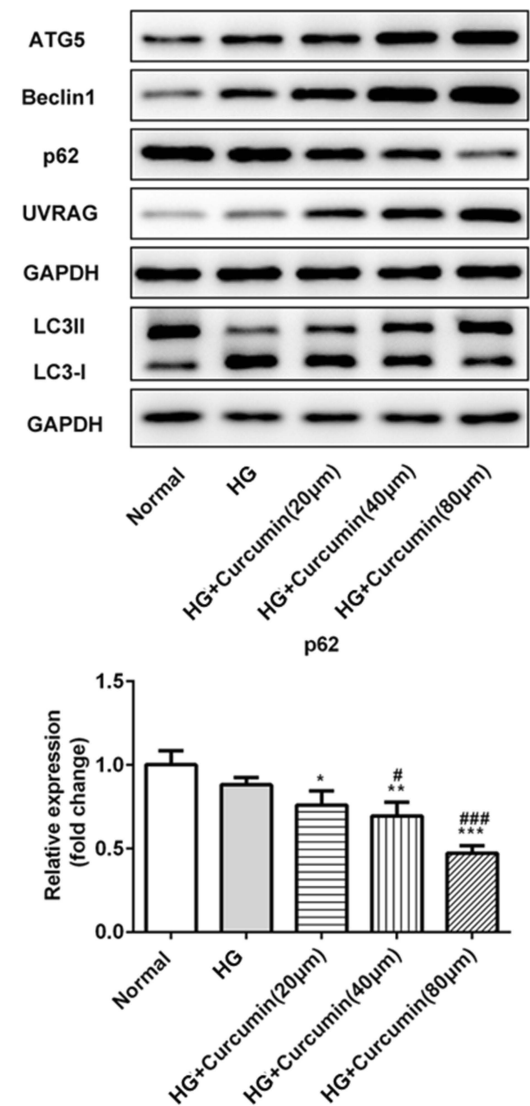

HG
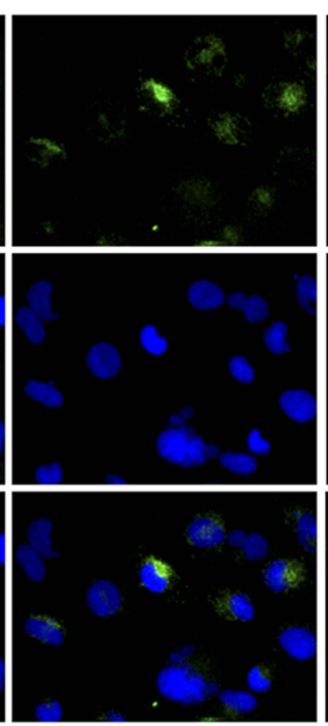

HG+Curcumin $(20 \mu \mathrm{m})$
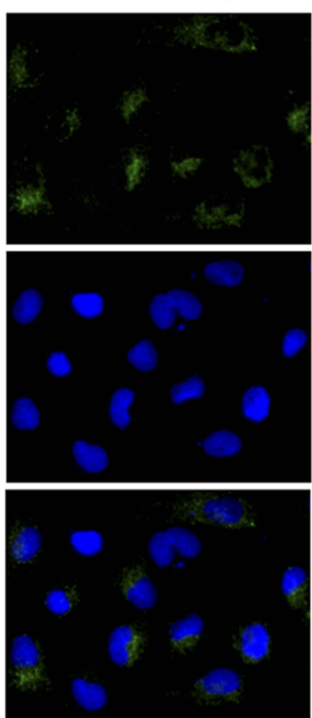

ATG5
HG+Curcumin $(40 \mu \mathrm{m})$
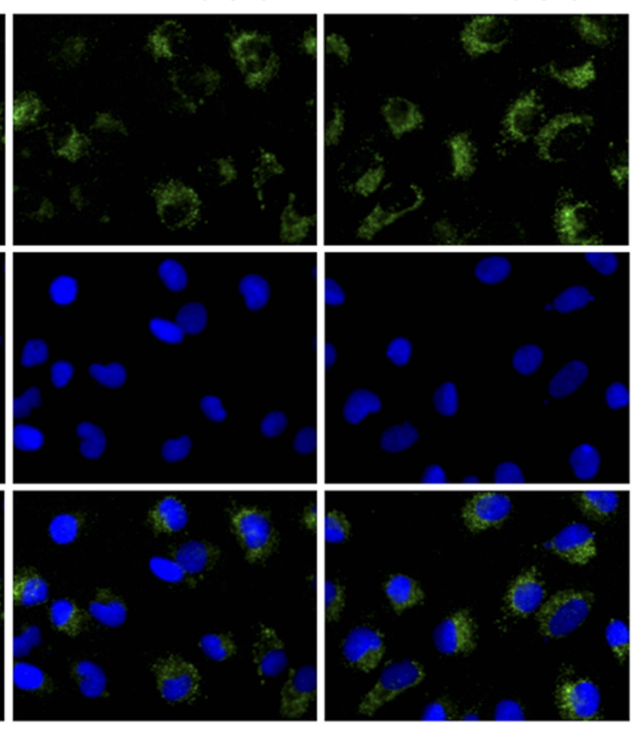

Beclin1
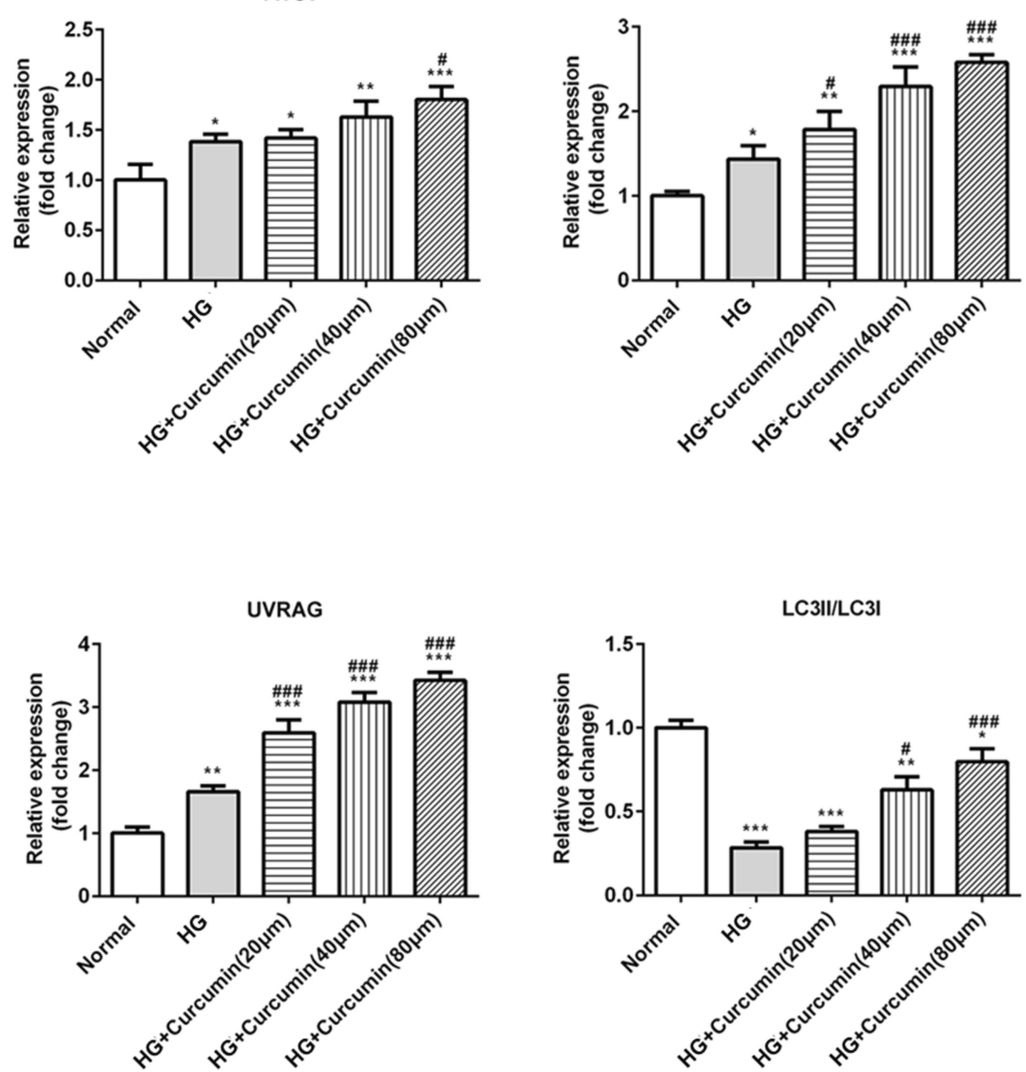

LC3II/LC3I

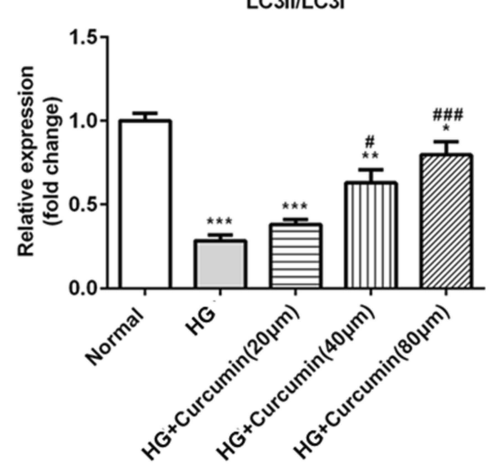

Figure 6 Effect of curcumin on podocyte autophagy and the expression of beclin I/UVRAG in medium containing high glucose. (A) The protein levels of LC3 were detected by immunofluorescence staining. (B) Western blot assay showed that the expression of beclinI, P62, UVRAG and ATG5 in podocytes. Data were shown as mean \pm SD. ${ }_{*}^{*} p<0.05$ VS Normal. ${ }^{\#} p<0.05$ VS HG: high glucose. (HG+cucumin): high glucose+curcumin. $* * p<0.01 . * * * p<0.00 \mathrm{I} .{ }^{\# \#} p<0.00 \mathrm{I}$.

podocyte injury via increasing the expression of podocalyxin and nephrin. Furthermore, curcumin suppressed apoptosis and promoted autophagy of renal cells via regulating apoptosis-related proteins and autophagy-related proteins. In vitro, we found that curcumin increased the podocyte proliferation, along with inhibited cell apoptosis and increased autophagy induced by high glucose. Thus, our study suggested that curcumin might exert protective effects via inhibiting podocyte apoptosis and accelerating cell autophagy in DN. 
Curcumin was safe, tolerated and possessed various biological activities. However, its poor absorption greatly affected its efficacy in treating some diseases. ${ }^{37}$ Thus, it was important to increase curcumin content in blood for studying its functions in DN. Thus, the dose of curcumin has been proved to have significant protective effects. Moreover, the dose of curcumin significantly improved renal damage and affected the autophagy pathway and apoptosis pathway in DN mice. Besides, in clinical trial, curcumin capsule significantly reduced proteinuria, inflammatory related factors in diabetic patients, which contained $500 \mathrm{mg}$ turmeric. ${ }^{38}$ Although active curcumin was comparatively lower, curcumin capsule could improve its bioavailability. Therefore, the dose of curcumin used based on preliminary animal experiments and clinical studies has significant effects for suppressing cell apoptosis and enhance autophagy in DN mice.

Apoptosis was a process whereby cells died in a controlled manner, which was involved in the development of DN. ${ }^{39,40}$ Podocyte apoptosis is an important pathogenic alteration that leads to podocyte loss in DN. Previous studies have shown that the interaction between apoptosis and DN included complex pathways and molecular and confirmed the important role of apoptosis pathways in DN. ${ }^{41-43}$ The B-cell lymphoma 2 family proteins are central regulators of intracellular apoptotic signaling cascades. In this study, WB showed that increased anti-apoptotic protein Bcl-2, and decreased pro-apoptotic protein Bax and caspase- 3 in the curcumin group than the DN group in vivo. Simultaneously, curcumin notably increased the expression of Bcl-2 and decreased the expression of Bax and caspase -3 in a dose-dependent manner in vitro. It replied that curcumin inhibited apoptosis possibly through a mitochondrial-mediated apoptotic pathway in podocytes induced by $\mathrm{HG}^{44,45}$

Podocytes were highly differentiated postmitotic cells and cell lesion seriously affected their regeneration abilities. Therefore, the fate of podocyte largely depended on its ability to respond to stimulus. Podocyte autophagy dysfunction has been reported to be responsible for the progression of $\mathrm{DN}$, which was a kind of effective protective mechanism on stress. ${ }^{46}$ Our study found that curcumin enhanced autophagy of podocyte exposed to high glucose via regulating autophagy-related proteins. It replied that curcumin enhanced the abilities of podocyte responding to high glucose.

Beclin 1 was involved in human diseases including cancer, heart disease, pathogen infection, and neurodegeneration. ${ }^{47-49}$ However, Beclin 1 was originally discovered not as an autophagy protein but as an interaction partner for the anti-apoptotic protein Bcl-2. ${ }^{50}$ Recent studies have demonstrated that anti- apoptotic protein Bcl-2 inhibit the autophagic function of Beclin 1 by binding to its $\mathrm{BH} 3$ domain. The subsequent studies reported that endogenous Bcl-2 probably regulated Beclin 1-mediated cell autophagy. ${ }^{51}$ In addition, the anti-apoptotic protein Bcl-2 reduces Beclin 1-dependent autophagy. ${ }^{52}$ Therefore, Bcl-2 family members also functioned as inhibitors for autophagic pathways. Similar to Beclin 1, UVRAG was also a tumor suppressor and was monoallelically deleted in human colon cancer cells and tissues. ${ }^{53}$ With respect to its function in autophagy, UVRAG was reported to act together with Beclin 1 to induce autophagosome biosynthesis. ${ }^{17}$ In this study, we found that curcumin significantly increased the expressions of beclin1, UVRAG and ATG5 and decreased the expression of p62 in DN mice. Then, podocyte study showed that curcumin significantly increased the expression levels of beclin1, UVRAG and ATG5 and decreased the expression of p62 in dose-dependent manner compared with the control group or high glucose group. Therefore, these data suggested that curcumin increased podocyte autophagy via regulating beclin1/UVRAG/Bcl-2 under the treatment of high glucose and in DN mouse.

In conclusion, this study indicated that curcumin reduced apoptosis and autophagy in DN renal tissues and podocyte exposed to high glucose via the regulation of Beclin1/UVRAG/Bcl2. Meanwhile, oral administration of curcumin improved albuminuria and the renal function in DN. These findings suggested the potential therapeutic effects of curcumin in DN.

\section{Acknowledgment}

The authors thank the partial support from the Grant No. 2019KY620.

\section{Disclosure}

The authors declare no conflict of interest.

\section{References}

1. Gnudi L, Coward RJM, Long DA. Diabetic nephropathy: perspective on novel molecular mechanisms. Trends Endocrinol Metab. 2016;27 (11):820-830. doi:10.1016/j.tem.2016.07.002

2. Al-rubeaan K, Siddiqui K, Alghonaim M, Youssef AM, AlNaqeb D. The Saudi Diabetic Kidney Disease study (Saudi-DKD): clinical characteristics and biochemical parameters. Ann Saudi Med. 2018;38 (1):46-56. doi:10.5144/0256-4947.2018.03.01.1010

3. Kim YI, Kim CH, Choi CS, et al. Microalbuminuria is associated with the insulin resistance syndrome independent of hypertension and type 2 diabetes in the Korean population. Diabetes Res Clin Pract. 2001;52 (2):145-152. doi:10.1016/S0168-8227(01)00228-5

4. Doshi SM, Friedman AN. Diagnosis and management of Type 2 diabetic kidney disease. Clin J Am Soc Nephrol. 2017;12(8):1366-1373. doi:10.2215/CJN.11111016 
5. Van Buren PN, Toto R. Current update in the management of diabetic nephropathy. Curr Diabetes Rev. 2013;9(1):62-77. doi:10.2174/ 157339913804143207

6. Lopez-vargas PA, Tong A, Howell M, Craig JC. Educational interventions for patients with CKD: a systematic review. Am J Kidney Dis. 2016;68(3):353-370. doi:10.1053/j.ajkd.2016.01.022

7. DeFronzo RA, Norton L, Abdul-ghani M. Renal, metabolic and cardiovascular considerations of SGLT2 inhibition. Nat Rev Nephrol. 2017;13(1):11-26. doi:10.1038/nrneph.2016.170

8. Lin JS, Susztak K. Podocytes: the weakest link in diabetic kidney disease? Curr Diab Rep. 2016;16(5):45. doi:10.1007/s11892-0160735-5

9. Muhldorfer J, Pfister E, Buttner-herold M, Klewer M, Amann K, Daniel C. Bi-nucleation of podocytes is uniformly accompanied by foot processes widening in renal disease. Nephrol Dialysis Transplant. 2018;33(5):796-803. doi:10.1093/ndt/gfx201

10. Jourdan T, Park JK, Varga ZV, et al. Cannabinoid-1 receptor deletion in podocytes mitigates both glomerular and tubular dysfunction in a mouse model of diabetic nephropathy. Diabetes Obes Metab. 2018;20(3):698-708. doi:10.1111/dom.13150

11. Yasuda-yamahara M, Kume S, Tagawa A, Maegawa H, Uzu T. Emerging role of podocyte autophagy in the progression of diabetic nephropathy. Autophagy. 2015;11(12):2385-2386. doi:10.1080/1554 8627.2015.1115173

12. Tagawa A, Yasuda M, Kume S, et al. Impaired podocyte autophagy exacerbates proteinuria in diabetic nephropathy. Diabetes. 2016;65 (3):755-767. doi:10.2337/db15-0473

13. Mizushima N, Komatsu M. Autophagy: renovation of cells and tissues. Cell. 2011;147(4):728-741. doi:10.1016/j.cell.2011.10.026

14. Roohbakhsh A, Shirani K, Karimi G. Methamphetamine-induced toxicity: the role of autophagy? Chem Biol Interact. 2016;260:163-167. doi:10.1016/j.cbi.2016.10.012

15. Li B, Chen $\mathrm{R}$, Chen $\mathrm{L}$, et al. Effects of DDIT4 in methamphetamine-induced autophagy and apoptosis in dopaminergic neurons. Mol Neurobiol. 2017;54(3):1642-1660. doi:10.1007/s12035015-9637-9

16. Ding Y, Choi ME. Autophagy in diabetic nephropathy. J Endocrinol. 2015;224(1):R15-30. doi:10.1530/JOE-14-0437

17. Funderburk SF, Wang QJ, Yue Z, Beclin T. 1-VPS34 complex-at the crossroads of autophagy and beyond. Trends Cell Biol. 2010;20 (6):355-362. doi:10.1016/j.tcb.2010.03.002

18. Liu Y, Zhang J, Wang Y, Zeng X. Apelin involved in progression of diabetic nephropathy by inhibiting autophagy in podocytes. Cell Death Dis. 2017;8(8):e3006. doi:10.1038/cddis.2017.414

19. Tian B, Wang Z, Zhao Y, et al. Effects of curcumin on bladder cancer cells and development of urothelial tumors in a rat bladder carcinogenesis model. Cancer Lett. 2008;264(2):299-308. doi:10.1016/j. canlet.2008.01.041

20. Ramsewak RS, DeWitt DL, Nair MG. Cytotoxicity, antioxidant and anti-inflammatory activities of curcumins I-III from Curcuma longa. Phytomedicine. 2000;7(4):303-308. doi:10.1016/S0944-7113(00) 80048-3

21. Zha W, Bai Y, Xu L, et al. Curcumin attenuates testicular injury in rats with streptozotocin-induced diabetes. Biomed Res Int. 2018;2018:7468019.

22. Hu S, Xu Y, Meng L, Huang L, Sun H. Curcumin inhibits proliferation and promotes apoptosis of breast cancer cells. Exp Ther Med. 2018;16(2):1266-1272. doi:10.3892/etm.2018.6345

23. Murray-stewart T, Dunworth M, Lui Y, Giardiello FM, Woster PM, Casero RA Jr. Curcumin mediates polyamine metabolism and sensitizes gastrointestinal cancer cells to antitumor polyamine-targeted therapies. PLoS One. 2018;13(8):e0202677. doi:10.1371/journal. pone.0202677

24. Wang K, Tan SL, Lu Q, et al. Curcumin suppresses microRNA-7641mediated regulation of p16 expression in bladder cancer. Am J Chin Med (Gard City N Y). 2018;1-12.
25. $\mathrm{Xu} \mathrm{H}$, Gong $\mathrm{Z}$, Zhou $\mathrm{S}$, et al. Liposomal curcumin targeting endometrial cancer through the NF-kappaB pathway. Cell Physiol Biochem. 2018;48(2):569-582. doi:10.1159/000491886

26. Chen G, Liu S, Pan R, et al. Curcumin attenuates gp120-induced microglial inflammation by inhibiting autophagy via the PI3K pathway. Cell Mol Neurobiol. 2018;38:1465-1477. doi:10.1007/s10571-018-0616-3

27. Seo SU, Woo SM, Lee HS, Kim SH, Min KJ, Kwon TK. mTORC1/2 inhibitor and curcumin induce apoptosis through lysosomal membrane permeabilization-mediated autophagy. Oncogene. 2018;37:5205-5220. doi:10.1038/s41388-018-0345-6

28. Wang WH, Chen J, Zhang BR, et al. Curcumin inhibits proliferation and enhances apoptosis in A549 cells by downregulating lncRNA UCA1. Pharmazie. 2018;73(7):402-407. doi:10.1691/ph.2018.8402

29. Yao Q, Ke ZQ, Guo S, et al. Curcumin protects against diabetic cardiomyopathy by promoting autophagy and alleviating apoptosis. $\mathrm{J} \mathrm{Mol}$ Cell Cardiol. 2018;124:26-34. doi:10.1016/j.yjmcc.2018.10.004

30. Soetikno V, Sari FR, Sukumaran V, et al. Curcumin decreases renal triglyceride accumulation through AMPK-SREBP signaling pathway in streptozotocin-induced type 1 diabetic rats. J Nutr Biochem. 2013;24(5):796-802. doi:10.1016/j.jnutbio.2012.04.013

31. Soetikno V, Watanabe K, Sari FR, et al. Curcumin attenuates diabetic nephropathy by inhibiting PKC- $\alpha$ and PKC- $\beta 1$ activity in streptozotocin-induced type I diabetic rats. Mol Nutr Food Res. 2011;55 (11):1655-1665. doi:10.1002/mnfr.v55.11

32. Gao P, Li L, Yang L, et al. 1 protein ameliorates diabetic nephropathy pathology through transcriptional repression of TGFbeta1. Sci Transl Med. 2019;11(510). doi:10.1126/scitranslmed.aav5519

33. Wang J R, Zhao JJ, Ye CL, et al. Hypolipemic and hypoglycemic effects of total triterpenoids from Psidium guajava leaves on type 2 diabetic rats. Chin J Pathophysiol. 2012;28(6):1109.

34. Zhao WC, Zhang B, Liao MJ, et al. Curcumin ameliorated diabetic neuropathy partially by inhibition of NADPH oxidase mediating oxidative stress in the spinal cord. Neurosci Lett. 2014;560:81-85. doi:10.1016/j.neulet.2013.12.019

35. Liu WT, Peng FF, Li HY, et al. Metadherin facilitates podocyte apoptosis in diabetic nephropathy. Cell Death Dis. 2016;7(11): e2477. doi:10.1038/cddis.2016.335

36. Jankowski M, Piwkowska A, Rogacka D, Audzeyenka I, Janaszakjasiecka A, Angielski S. Expression of membrane-bound NPP-type ecto-phosphodiesterases in rat podocytes cultured at normal and high glucose concentrations. Biochem Biophys Res Commun. 2011;416 (1-2):64-69. doi:10.1016/j.bbrc.2011.10.144

37. Zhu LN, Mei X, Zhang ZG, Xie YP, Lang F. Curcumin intervention for cognitive function in different types of people: a systematic review and meta-analysis. Phytother Res. 2019;33(3):524-533. doi:10.1002/ptr.6257

38. Khajehdehi P, Pakfetrat M, Javidnia K, et al. Oral supplementation of turmeric attenuates proteinuria, transforming growth factor-beta and interleukin- 8 levels in patients with overt type 2 diabetic nephropathy: a randomized, double-blind and placebo-controlled study. Scand J Urol Nephrol. 2011;45(5):365-370. doi:10.3109/00365599.2011.585622

39. Feng Y, Chen S, Xu J, et al. Dysregulation of IncRNAs GM5524 and GM15645 involved in high-glucose-induced podocyte apoptosis and autophagy in diabetic nephropathy. Mol Med Rep. 2018. doi:10.3892/ mmr.2018.9412

40. Sifuentes-franco S, Padilla-tejeda DE, Carrillo-ibarra S, Mirandadiaz AG. Oxidative stress, apoptosis, and mitochondrial function in diabetic nephropathy. Int J Endocrinol. 2018;2018:1875870.

41. Tian N, Gao Y, Wang X, et al. Emodin mitigates podocytes apoptosis induced by endoplasmic reticulum stress through the inhibition of the PERK pathway in diabetic nephropathy. Drug Des Devel Ther. 2018;12:2195-2211. doi:10.2147/DDDT.S167405

42. Chang WW, Liang W, Yao XM, et al. Tumour necrosis factor-related apoptosis-inducing ligand expression in patients with diabetic nephropathy. J Renin Angiotensin Aldosterone Syst. 2018;19(3):14703203 18785744. doi: $10.1177 / 1470320318785744$ 
43. Wang Y, Li H, Song SP. beta-arrestin 1/2 aggravates podocyte apoptosis of diabetic nephropathy via Wnt/beta-Catenin pathway. Med Sci Monitor. 2018;24:1724-1732.

44. Lin -H-H, Chen J-H, Huang -C-C, Wang C-J. Apoptotic effect of 3,4-dihydroxybenzoic acid on human gastric carcinoma cells involving JNK/p38 MAPK signaling activation. Int $J$ Cancer. 2007;120 (11):2306-2316. doi:10.1002/(ISSN)1097-0215

45. Scorrano L, Korsmeyer SJ. Mechanisms of cytochrome c release by proapoptotic BCL-2 family members. Biochem Biophys Res Commun. 2003;304(3):437-444. doi:10.1016/S0006-291X(03)00615-6

46. Hartleben B, Gödel M, Meyer-schwesinger C, et al. Autophagy influences glomerular disease susceptibility and maintains podocyte homeostasis in aging mice. J Clin Invest. 2010;120(4):1084-1096. doi:10.1172/JCI39492

47. Qin Z, Yu X, Lin M, Wu J, Ma S, Wang N. Prognostic and clinicopathological value of Beclin-1 expression in hepatocellular carcinoma: a meta-analysis. World J Surg Oncol. 2018;16(1):170.

48. Naguib M, Rashed LA. Serum level of the autophagy biomarker Beclin-1 in patients with diabetic kidney disease. Diabetes Res Clin Pract. 2018;143:56-61. doi:10.1016/j.diabres.2018.06.022
49. Fernandez AF, Sebti S, Wei Y, et al. Disruption of the beclin 1-BCL2 autophagy regulatory complex promotes longevity in mice. Nature. 2018;558(7708):136-140. doi:10.1038/s41586-018-0162-7

50. Liang XH, Kleeman LK, Jiang HH, et al. Protection against fatal Sindbis virus encephalitis by beclin, a novel Bcl-2-interacting protein. $J$ Virol. 1998;72(11):8586-8596. doi:10.1128/JVI.72.11.8586-8596.1998

51. Maiuri MC, Criollo A, Tasdemir E, et al. BH3-only proteins and $\mathrm{BH} 3$ mimetics induce autophagy by competitively disrupting the interaction between Beclin 1 and Bcl-2/Bcl-X(L). Autophagy. 2007;3 (4):374-376. doi:10.4161/auto.4237

52. Pattingre S, Tassa A, Qu X, et al. Bcl-2 antiapoptotic proteins inhibit Beclin 1-dependent autophagy. Cell. 2005;122(6):927-939. doi:10.1016/j.cell.2005.07.002

53. Liang $\mathrm{C}$, Feng $\mathrm{P}, \mathrm{Ku} \mathrm{B}$, et al. Autophagic and tumour suppressor activity of a novel Beclin1-binding protein UVRAG. Nat Cell Biol. 2006;8(7):688-699. doi:10.1038/ncb1426

\section{Publish your work in this journal}

Diabetes, Metabolic Syndrome and Obesity: Targets and Therapy is an international, peer-reviewed open-access journal committed to the rapid publication of the latest laboratory and clinical findings in the fields of diabetes, metabolic syndrome and obesity research. Original research, review, case reports, hypothesis formation, expert opinion and commentaries are all considered for publication. The manuscript management system is completely online and includes a very quick and fair peer-review system, which is all easy to use. Visit http://www.dovepress.com/testimonials.php to read real quotes from published authors.

Submit your manuscript here: https://www.dovepress.com/diabetes-metabolic-syndrome-and-obesity-targets-and-therapy-journal 